\title{
Duplicate publications: A sample of redundancy in the Journal of Urology
}

\author{
Kiara K. Hennessey, MD, FRCSC; Aaron R. Williams, MD; Kourosh Afshar, MD, FRCSC, FAAP; Andrew E. \\ MacNeily MD FRCSC FAAP
}

Department of Urologic Sciences, University of British Columbia, Vancouver, BC

See related article on page 181.

Cite as: Can Urol Assoc J 2012;6(3):177-80. htrp://dx.doi.org/10.5489/cuaj.11265

\section{Abstract}

Purpose: Redundant publications occur when authors publish a partial or complete duplicate of data from an existing manuscript. The push for academic advancement in medicine may result in redundant publications that erode the quality of literature. We sampled the extent of redundancy within the Journal of Urology. Methods: Original articles published in the Journal of Urology in 2006 were reviewed. MEDLINE was used to identify suspected duplicate publications by combining the last names of the first, second and last authors with keywords provided by the article. Results were limited to 2004 to 2008 . Two investigators reviewed the suspected duplicate publications and classified them as duplicate, probable duplicate and salami-slicing.

Results: We screened 723 original articles. Of these original articles, $13(1.8 \%)$ had some form of redundancy. One $(0.1 \%)$ original article had a duplicate article, $5(0.7 \%)$ original articles had probable duplicates, and 7 (1\%) original articles were salamisliced. The proportion of redundant articles published prior to, and following, their 2006 index article was 5/13 (38.5\%) and 7/13 $(53.8 \%)$, respectively. One duplicate $(7.7 \%)$ was published in the same month as its index.

Conclusion: Detection of redundant publications is a laborious process for reviewers and editors. This sampling of the Journal of Urology revealed that the duplication rate in this journal is small, but significant. Further assessment of the urological literature is warranted.

\section{Introduction}

A redundant (or duplicate) manuscript is the publication of a paper that overlaps substantially with one already published in print or electronic media and shares most of the same authors. ${ }^{1,2}$ Recently, the criteria for a duplicate publication have been clearly defined by the editors of Surgery and should be considered fraudulent except if: (1) they are only published in abstract form, (2) a manuscript extends an original database by $50 \%$ or more, or (3) a manuscript has been published previously in a non-English language journal. ${ }^{3}$

Redundant publication may result from a "publish or perish" culture, in which the number of publications in peerreviewed journals is used to measure scholarly achievement. This is a reality of academic life necessary for career progression. ${ }^{4}$

The phenomenon of duplicate publications has been condemned in a wide range of medical journals. More recently, several surgical disciplines, including general surgery, plastic surgery, orthopedics, otolaryngology, ophthalmology and hand surgery, have examined the extent of redundancy in the literature of their respective fields. ${ }^{4-8}$ There has not been an evaluation of the extent of redundant publication in the urological literature to date. This study was designed to sample the incidence, spectrum and salient characteristics of redundant publications in urology. Analysis of all original articles published in a leading urology journal in 2006 was chosen as our study sample of the urological literature.

\section{Methods}

We reviewed 723 original index articles (excluding editorials, reviews, urological surveys and letters to the editor) published in 2006 in the Journal of Urology. We then performed a Medline search to identify suspected duplicate publications. As our search strategy, we combined the last names of the first, second and last authors with the keywords provided by the original article. Search results were limited to 2004 to 2008. Papers were defined as "suspected" duplicate publications if they were found to address the same topic as the index article and shared either the same methodology or the same results or conclusions. ${ }^{3}$ Full versions of all suspected duplicate publications were then retrieved and two senior investigators (KA, AEM), each blind to the other, reviewed the suspected duplicate publications and classified 
them. We used the classification system described by Schein and colleagues: ${ }^{3}$ "duplicate" (identical materials, methods, results and conclusions), "probable duplicate" (almost identical materials, methods, results and conclusions), and "salami-slicing" (portions of index article repeated or continued).

\section{Results}

Of the 723 original index articles from The Journal of Urology in 2006, 28 (3.9\%) were related to 31 suspected duplicate publications. Most of the 28 index articles were related to only one suspected duplicate; however, 3 index articles were each related to 2 suspected duplicates.

Review of the full-text versions of both the suspected duplicate and original index articles revealed that 13 of the 31 suspected duplicates were confirmed as a redundant publication by the reviewers. There were a total of four manuscripts which one reviewer felt were salami-slicing. The other reviewer felt they were not redundant articles. The complete manuscripts were reviewed jointly and the data from each article were reviewed in detail. The consensus was that all four of these manuscripts should be classified as salami-slicing.

The 13 confirmed redundant publications were derived from 13 original index articles. One (3.2\%) redundant article was classified as a complete duplicate, $5(16.1 \%)$ articles as probable duplicates, and $7(22.6 \%)$ as salami-sliced. Overall, of the 723 original index articles in The Journal of Urology in 2006, 13 (1.8\%) index articles had some form of redundant publication and only one $(0.1 \%)$ had an actual duplicate publication involving an identical article (Table 1). The proportion of redundant articles published prior to, and following, their index article was 5/13 (38.5\%) and $7 / 13(53.8 \%)$, respectively. One redundant article $(7.7 \%)$ was published in the same month as its index article. Of the 13 articles, 10 (77\%) were published within the same year.

\section{Discussion}

Redundant publications have many negative impacts. In addition to being academically unethical, multiple publications of the same work can artificially inflate the scientific

\begin{tabular}{lccc}
\hline Table 1. Redundancy in the Journal of Urology in 2006 \\
\hline $\begin{array}{l}\text { Classification } \\
\text { of suspected } \\
\text { duplicates }\end{array}$ & Total & $\begin{array}{c}\text { Percentage } \\
\text { of total index } \\
\text { articles from } \mathbf{J} \\
\text { Urol in } \mathbf{2 0 0 6} \text { (723) }\end{array}$ & $\begin{array}{c}\text { Percentage of } \\
\text { total suspected } \\
\text { duplicates (31) }\end{array}$ \\
\hline $\begin{array}{l}\text { Duplicated } \\
\text { Probable duplicate }\end{array}$ & 1 & 0.1 & 3.2 \\
$\begin{array}{l}\text { Salami slicing } \\
\text { Non duplicate }\end{array}$ & 7 & 0.7 & 16.1 \\
$\begin{array}{l}\text { Percent index } \\
\text { articles associated } \\
\text { with duplicate }\end{array}$ & 18 & 1.0 & 22.6 \\
\hline
\end{tabular}

literature, add clutter, exaggerate the significance of findings, displace the work of others, waste time and resources of editors and reviewers, interfere with the statistical methods used to generate evidence-based recommendations, and distort the academic reward system..$^{4,5}$ Publishing duplicate work also breaches copyright laws. ${ }^{4}$

Since the study of redundancy in the general surgery literature demonstrated that almost one in every six original articles published in leading surgical journals represents some form of redundancy, ${ }^{3}$ several studies have identified and assessed the scope of this problem within other surgical specialties (Table 2 ). In our study, $1.8 \%$ of publications in The Journal of Urology in 2006 were found to have some degree of redundancy. Only one of the 13 suspected duplicates was a complete duplicate, in which the order of the authors was rearranged. This rate of redundancy compares very favourably to the above-mentioned specialties. However, it should be noted that comparison of redundancy rates between different specialties is subject to error since methodologies used to assess duplication are not uniform. ${ }^{4}$ In addition, considering the smaller size of the urological community and its body of literature compared to general surgery, it is likely easier to detect duplication, which may deter attempts at such activity.

Our assessment of the timing of duplicate publications revealed that most were published essentially at the same time as their index articles. When editors receive a manuscript for review, a process which takes on average 4.3 months, 9,10 the index has not yet been published and is therefore undetectable by conventional search methods. ${ }^{4}$

\begin{tabular}{|c|c|c|}
\hline Surgical specialty & Publication & Degree of redundancy \\
\hline General surgery & Schein $\mathrm{M}$ et al. Redundant surgical publications: tip of the iceberg? ${ }^{3}$ & $14.0 \%$ \\
\hline Otolaryngology & Rosenthal E et al. Duplicate publications in the otolaryngology literature. ${ }^{7}$ & $8.5 \%$ \\
\hline Orthopedic surgery & $\begin{array}{l}\text { Gwilym SE et al. One in } 13 \text { 'original' articles in the Journal of Bone and Joint Surgery are } \\
\text { duplicate or fragmented publications. }{ }^{6}\end{array}$ & $7.6 \%$ \\
\hline Hand surgery & Chennagiri RJ et al. Duplicate publication in the Journal of Hand Surgery. ${ }^{8}$ & $2.0 \%$ \\
\hline Ophthalmology & $\begin{array}{l}\text { Mojon-Azzi S et al. Redundant publications in scientific ophthalmologic journals, the tip of } \\
\text { the iceberg? }\end{array}$ & $1.4 \%$ \\
\hline Plastic surgery & Durani P. Duplicate Publications: redundancy in plastic surgery literature. ${ }^{4}$ & $0.7 \%$ \\
\hline
\end{tabular}


This pattern was demonstrated in our study which identified that most duplicates $(77 \%)$ were published within the same year as their index article.

There are some situations where duplicate publication is not considered fraudulent. As mentioned, publishing in abstract form, extension of the original database by more than $50 \%$ and publishing in a different language are acceptable forms of redundancy. ${ }^{1}$ In addition, distribution of important clinical guidelines affecting more than one group of specialties, and even "salami-slicing" may be considered reasonable if each slice addresses distinct issues. An example includes multiple reports from a single large multicentre trial with several important outcomes. An argument to legitimize all of these variants as ethical duplications can be made as long as each publication is deliberately and clearly cross-referenced.

If quantity, not quality of articles, is the primary requirement for academic advancement, the problem of redundancy is likely to persist. Readers, patients, editors and reviewers deserve to be able to trust that what they are reading is original, unless there is a clear statement that the author and editor are intentionally republishing an article. However, the primary prevention of duplicate publications will require changes in the system of rewards and penalties within academic institutions and government agencies. ${ }^{11,12}$ Nevertheless, editors can take preventive measures to help combat this problem, including both passive and active strategies. Strategies include: establishing accurate definitions of redundancy, publishing warnings about measures adopted by journals and establishing and publishing consequences for offending authors (i.e., retraction, reprimanding, reporting). The COPE (Committee on Publication Ethics) has developed algorithms for "Suspected plagiarism in a submitted manuscript" and "Suspected redundant publication in a submitted manuscript." 2 These flowcharts outline the recommended steps of action against suspected duplicates and illustrate the extent of the editors' and publishers' responsibilities. The editor of the Journal of Urology recently outlined the Journal's approach to the detection of duplicate publications and the disciplinary steps of action for at-fault authors. ${ }^{13}$ Resources used by this journal include the COPE principles and guidelines.

More recently, attention has focused on electronic tools to help busy editors in screening submissions for potential duplication. For example, Errami and colleagues ${ }^{14}$ have created "Déjà vu," a publicly available database of highly similar Medline citations identified by the text similarity search engine eTBLAST. ${ }^{15}$ eTBLAST is also freely accessible. Following manual verification, highly similar citation pairs are classified into various categories ranging from duplicates with different authors to sanctioned duplicates. "Déjà vu" also contains user-provided commentary and supporting information to substantiate each document's categoriza- tion. ${ }^{15}$ CrossCheck is another electronic plagiarism detection tool that uses iThenticate algorithms ${ }^{16}$ to rapidly compare the text from scanned manuscripts both with a database of published articles from the participating CrossCheck publishers and with the Internet. It finds matched sections of duplicate text and gives editors an overall "Similarity Index" (the percentage of the text in the manuscript being scanned that appears to have been derived from other sources). CrossCheck is a publisher-led initiative that is available to paying members.

We acknowledge the limitations of our study. We only sampled one journal from one year with a four-year search window. Nevertheless, we were able to screen several thousands of articles based on more than 700 index manuscripts. We did not attempt to estimate the true incidence of duplicate publications in the entire urologic literature. This type of search is very laborious.

\section{Conclusion}

It is encouraging that our sampling of the Journal of Urology found a low level of redundancy. However, this study represents a sampling of only one year of publications from one high quality journal in the urological literature. Assessment of lower impact urological journals with a less stringent review process may reveal a higher rate of redundancy. A broader assessment of the urological literature would provide a more accurate assessment of duplication in our field. It is very important to raise awareness of, and help discourage, future duplicate publications.

Competing interests: None declared.

This paper has been peer-reviewed.

\section{References}

1. International Committee of Medical Journal Editors. Uniform requirements for manuscripts submitted to biomedical journals: writing and editing for biomedical publication, http://www.icmie.org/ (Accessed May 1, 2012).

2. Committee on Publication Ethics. Guidelines on Good Publication and Code of Conduct. http://www. publicationethics.org/resources/guidelines (Accessed May 1, 2012).

3. Schein M, Paladugu R. Redundant surgical publications: tip of the iceberg? Surgery 2001;129:655-61. http://dx.doi.org/10.1067/msy.2001.114549

4. Durani P. Duplicate Publications: redundancy in plastic surgery literature. J Plast Reconstr Aesthet Surg 2006;59:975-7. http://dx.doi.org/10.1016/i.bps.2005.11.039

5. Mojon-Azzi S, Jiang $X$, Wagner $U$, et al. Redundant publications in scientific ophthalmologic journals, the tip of the iceberg? Ophthalmology 2004; 11:863-6. http://dx.doi.org/10.1016/i.ophtha.2003.09.029

6. Gwilym SE, Swan MC, Giele H. One in 13 'original' articles in the Journal of Bone and Joint Surgery are duplicate or fragmented publications. J Bone Joint Surg Br 2004;86:743-5.

7. Rosenthal E, Masdon JL, Buckman C, et al. Duplicate publications in the otolaryngology literature. Laryngoscope 2003;113:772-4.

8. Chennagiri RJ, Critchley P, Giele H. Duplicate publication in the Journal of Hand Surgery. J Hand Surg [Br] 2004;29:625-8. 
Hennessey et al.

9. Errami M, Garner H. A tale of two citations. Nature 2008;451:397-9. http://dx.doi org/ $10.1038 / 4513970$

10. Pop H, Fesoernab S, Ball D, et al. Duplicate Presentations on Prostate Cancer at American Urological Association and European Association of Urology Annual Meetings. J Urol 2009;182:674-9. http:// dx.doi.org/10.1016/i.juro.2009.04.024

11. Angell M. Publish or perish: a proposal. Ann Int Med 1986;104:261-2.

12. Petersdorf RG. Is the establishment defensible? N Eng J Med 1983;309:1053-7. http://dx.doi. org/10.1056/NEJM198310273091711

13. Steers W. Coping with publication ethics. J Urol 2011;196:369-70. http://dx.doi.org/10.1016/i. juro.2011.05.011
14. Errami $M$, Sun Z, Long $T$, et al. Deja vu: a database of highly similar citations in the scientific literature. Nucleic Acids Res 2008;0921-1.

15. Lewis J, Ossowski S, Hicks J, et al. Test similarity: an alternative way to search MEDLINE. Bioinformatics 2006;22:2298-304. http://dx.doi.org/10.1093/bioinformatics/bt388

16. Crosscheck. http://www.crossref.org/crosscheck/index.html (Accessed May 1, 2012).

Correspondence: Dr. Andrew E MacNeily, Division of Pediatric Urology, KO-134 BC Children's Hospital, 4480 0ak St., Vancouver, BC V6H 3V4; amacneily@cw.bc.ca 